\title{
マルチバイオイメージング用ナノ粒子プローブの開発
}

\section{Preparation of Nanoparticle Probes for Multimodal Bio-imaging}

\section{2}

研究代表者慶應義塾大学理工学部応用化学科

准教授 磯 部 徹 彦 Tetsuhiko Isobe

The nanoparticles of solid solutions between $\mathrm{Y}_{3} \mathrm{Al}_{5} \mathrm{O}_{12}$ (YAG) and $\mathrm{Gd}_{3} \mathrm{Al}_{5} \mathrm{O}_{12}$ (GAG) are synthesized from yttrium acetate tetrahydrate, gadolinium acetate tetrahydrate and aluminum isopropoxide at different $\mathrm{Y} / \mathrm{Gd}$ atomic ratios in 1,4-butanediol by autoclave treatment at $300^{\circ} \mathrm{C}$ for 2 h, i.e., by the glycothermal reaction. On the other hand, $\mathrm{Yb}^{3+}$ doped $\mathrm{Y}_{3} \mathrm{Al}_{5} \mathrm{O}_{12}$ (YAG: $\mathrm{Yb}^{3+}$ ) nanoparticles are prepared from yttrium acetate tetrahydrate, ytterbium acetate tetrahydrate and aluminum isopropoxide in 1,4-butanediol by autoclave treatment at $300^{\circ} \mathrm{C}$ for $2 \mathrm{~h}$. Moreover, $\mathrm{Gd}^{-}$ YAG and Gd-YAG:Yb ${ }^{3+}$ nanoparticles are prepared from the mixture of gadolinium acetate tetrahydrate and either YAG or YAG:Yb ${ }^{3+}$ colloidal solution by the same autoclave treatment as YAG:Yb ${ }^{3+}$. Properties of structure, near infrared photoluminescence and magnetic resonance contrast enhancement are characterized for as-prepared nanoparticles. The solid solutions between YAG and GAG work as $T_{2}$ contrast agent for magnetic resonance imaging, while Gd-YAG works as $T_{1}$ and $T_{2}$ contrast agents. Gd-YAG:Yb ${ }^{3+}$ nanoparticles work as $T_{1}$ and $T_{2}$ contrast agents like Gd-YAG nanoparticles, and show near infrared emission at $1030 \mathrm{~nm}$ due to the $\mathrm{f}-\mathrm{f}$ transition of $\mathrm{Yb}^{3+}$ under the $940 \mathrm{~nm}$ excitation using near infrared laser diode.

\section{研究目的}

蛍光体のナノサイズ化によって，今までのミクロン サイズの蛍光体では利用されなかった応用分野が開拓 されている。そのひとつが生化学分野への応用である。 $\mathrm{CdSe} / \mathrm{ZnS}$ 量子ドットのような紫外光励起 - 可視光発 光の蛍光体や, 近赤外領域で励起や発光を行うナノ蛍 光体を生体分子検出用蛍光プローブとして検討してい る。近赤外領域は「生体の空」と呼ばれており, 生体 組織による吸収が少ないため, 自家蛍光を抑制して検 出感度を向上させることができる ${ }^{1-2)}$ 。波長600～1200 $\mathrm{nm}$ の生体の光吸収が少ない領域を利用する近赤外蛍 光画像法は大きな期待のある画像法のひとつである。
このような近赤外蛍光画像法に利用できるナノ粒子と

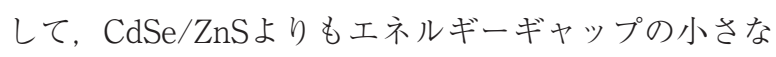
$\mathrm{CdTe}_{\mathrm{X}} \mathrm{Se}_{1-\mathrm{X}} / \mathrm{CdS}^{3)}$, シリカ被覆して近赤外蛍光を発 するランタノイド $(\mathrm{Ln})$ イオンをドープした $\mathrm{LaF}_{3}$ : $\mathrm{Ln}^{2)}$ ，アップコンバージョンを利用した $\mathrm{NaYF}_{4}: \mathrm{Yb}$, $\mathrm{Er}^{4)}$ や $\mathrm{LuPO}_{4}: \mathrm{Yb}^{\mathrm{T}} \mathrm{Tm}^{5)}$ などが研究されている。そ の他, ナノダイヤモン ド6) やSi广ノ粒子 ${ }^{7)}$ も近赤外発 光蛍光粒子として検討されている。

一方, 磁気共鳴画像法はプロトン $\left({ }^{1} \mathrm{H}\right)$ の磁気モ ーメントの緩和を測定して画像化を行う非侵襲の断層 撮影法である。常磁性 $\mathrm{Gd}^{3+}$ イオンや超常磁性ナノ粒子 は磁気共鳴造影剤として利用されている。磁気共鳴画 像 (MRI) で得られる解像度はmm程度であり, より 
詳細に観察するためには他の画像法と組み合わせるこ とが有効である。このような複数の画像法を組み合わ せるイメージングは, マルチモーダルイメージングと 呼ばれる。例えば，蛍光と磁気共鳴（MR）の両者の イメージングを用いる場合に，ひとつの試薬（プロー ブ）を用いて観察すると相補的な画像を得ることがで きる8)。そのようなプローブとして，ナノ蛍光体に MRの機能を付与することが検討され始めている。例 えば，量子ドットと Gd錯体との組み合わせ9)-13) や， 蛍光を付与したGd化合物ナノ粒子が検討されている 14)。蛍光とMRの両者によって組織の情報を取得する 方法は，X線や放射性元素を用いない安全性の高い方 法である。

本研究では，近赤外蛍光㧍よび磁気共鳴 (MR) 造 影能の二つの機能を併せ持つガーネット型構造を有す るナノ粒子の作製を検討した。まず，MR造影能を有 する母体を得るために， $\mathrm{T}_{1}$ 造影剤として広く利用さ れている $\mathrm{Gd}^{3+}$ を含んだナノ粒子として (i) $\mathrm{Y}_{3} \mathrm{Al}_{5} \mathrm{O}_{12}$ (YAG) および $\mathrm{Gd}_{3} \mathrm{Al}_{5} \mathrm{O}_{12}(\mathrm{GAG})$ の全率固溶体（(GY) $\mathrm{AG}$ )のナノ粒子，および（ii）予め作製したYAGナ ノ粒子に $\mathrm{Gd}^{3+}$ を添加して作製したナノ粒子 (Gd-YAG) を作製し，それらのMR造影能を比較検討した。さら に，(iii） $\mathrm{Yb}^{3+}$ をドープしたYAG $\left(\mathrm{YAG}: \mathrm{Yb}^{3+}\right)$ ナノ 粒子にGd ${ }^{3+}$ を添加して作製したナノ粒子（Gd-YAG： $\left.\mathrm{Yb}^{3+}\right)$ に関するMR造影能㧍よび近赤外蛍光を検討し た。このほかに, $\mathrm{Gd}_{3} \mathrm{Ga}_{5} \mathrm{O}_{12}(\mathrm{GGG})$ 拈よび $\mathrm{Gd}_{3} \mathrm{Ga}_{5} \mathrm{O}_{12}$ : $\mathrm{Yb}^{3+}\left(\mathrm{GGG}: \mathrm{Yb}^{3+}\right)$ についても検討した。

\section{研究成果の概要}

\section{1. 実験方法}

\section{1 （GY） AG固溶体ナノ粒子の作製}

酢酸イットリウム 4 水和物（酢酸 $\mathrm{Y}$ ), 酢酸ガドリ 二ウム 4 水和物（酢酸 $\mathrm{Gd} ）(\mathrm{Gd} /(\mathrm{Y}+\mathrm{Gd})=0-100 \%)$, アルミニウムイソプロポキシド（AIP）を1,4-ブタン ジオール（1,4-BD）に投入し，オートクレーブにセ ットした。300 rpmで覺拌しながら室温から $300^{\circ} \mathrm{C}$ ま で90 minで昇温し， 2 h保持した。室温まで空冷した コロイド溶液を，95\%メタノール変性アルコールによ り遠心洗浄を行い, $50^{\circ} \mathrm{C}$ で1 day乾燥させ粉末状の （GY）AGナノ粒子を得た。

\subsection{Gd-YAG（Gd-YAG:Yb3+）ナノ粒子の作製}

酢酸Yまたは酢酸Yと酢酸イッテルビウム 4 水和物

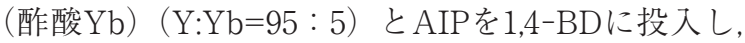
同様の操作によりYAG（またはYAG： $\mathrm{Yb}^{3+}$ ) コロイ ド溶液を得た。これに酢酸 $\mathrm{Gd}$ と1,4-BDを加え再度才 一トクレーブ処理し, 前述と同様の洗浄・乾燥を行う ことでGd-YAG（またはGd-YAG： $\mathrm{Yb}^{3+}$ ) ナノ粒子を 得た。

\section{$1.3 \mathrm{GGG}$ おびGGG:Yb3+}

1.1 に記載されたグリコサーマル法とほほ同じ手法 で合成を実施した。なお，原料には，酢酸 $\mathrm{Gd}$ ，酢酸 Yb拈よびガリウムアセチルアセトナートを用いた。

\section{2. 結果および考察}

\section{1 （GY） AG固溶体ナノ粒子}

Fig. 1に（GY）AG（Gd25\%）ナノ粒子およびGAG （Gd100\%）ナノ粒子のSEM像を示す。それぞれの画

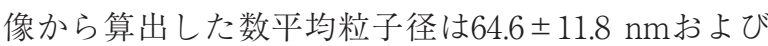
$125.1 \pm 19.7 \mathrm{~nm}$ であった。両試料のX線回折ピークは 単相のガーネット構造に帰属された。また，Fig. 2に 示すように，(GY）AG固溶体ではGd濃度の増加に伴 い第一強線である（420）ピークは低角度側にシフト

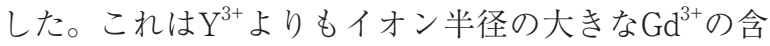
有量が増加することによって面間隔が増大したことに 起因する。
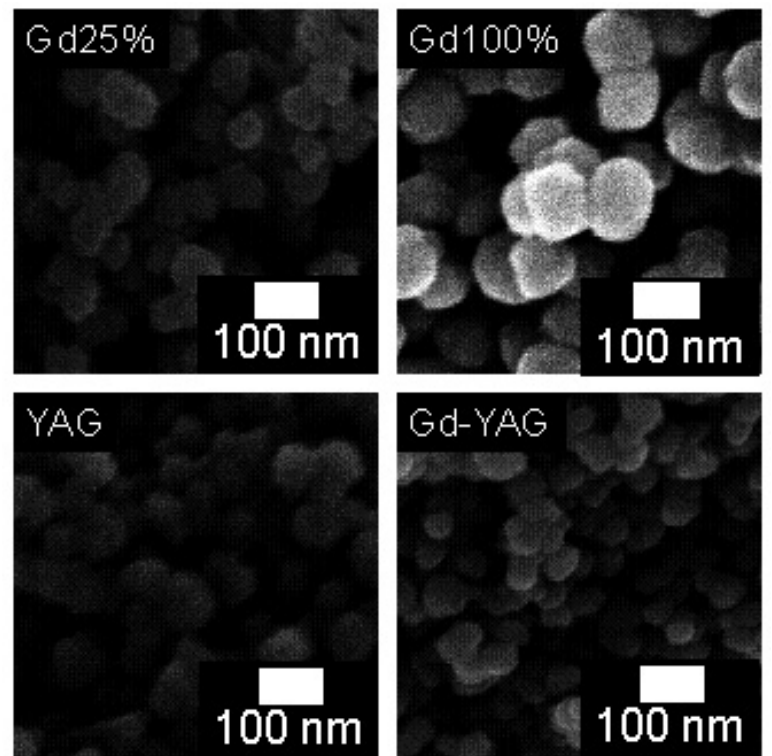

Fig. 1 SEM images of (GY) AG, YAG and GdYAG. 


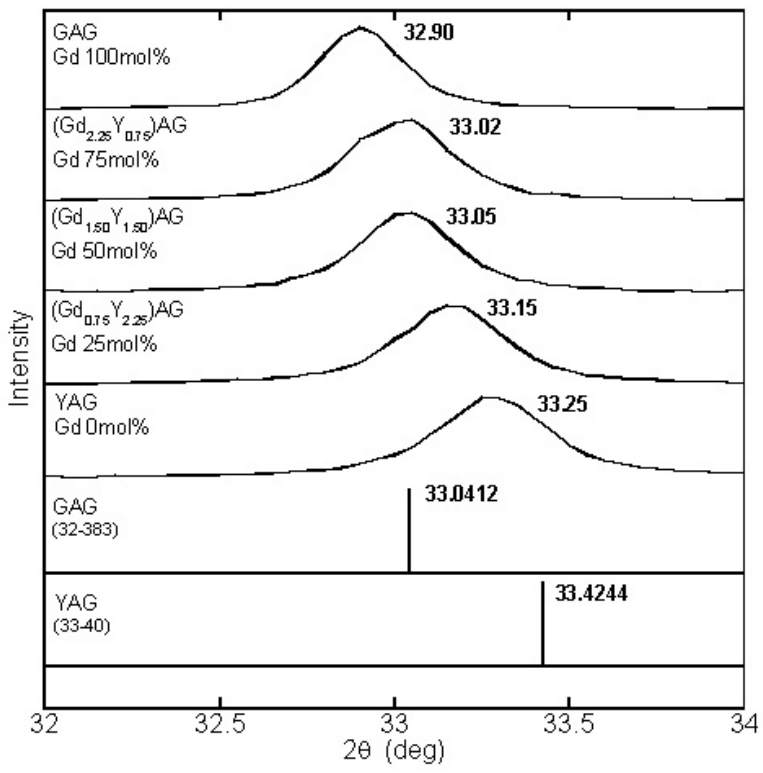

Fig. 2 X-ray diffraction profiles of solid-solution between YAG and GAG at different Gd concentrations.

Fig. 3にアガロースゲルに分散させたナノ粒子の $\mathrm{MR}$ 造影画像を示す。 $\mathrm{T}_{2}$ (陰性) 画像ではGdの含有濃 度に関わらず，粒子濃度が増大するに従って，画像は より暗くなった。しかし， $\mathrm{T}_{1}$ （陽性）画像では，粒 子濃度が増大するに従い像が暗くなるという, 従来の Gd錯体のT 1 造影剤とは逆の傾向を示した。これには 粒子中のGd含有量に応じた次の 2 つの原因が考えら れる。(1)Gd含有量が低濃度の場合, 粒子表面に存在 するGdが僅かであり，水分子の ${ }^{1} \mathrm{H}$ と粒子表面 $\mathrm{Gd}^{3+}$ と の双極子 - 双極子相互作用による磁気緩和が不十分で ある。(2)Gd含有量が高濃度の場合, (GdY) AG固溶 体ナノ粒子の磁化率効果が大きく, $\mathrm{T}_{2}$ 緩和の影響を 大きく受けて正常な $\mathrm{T}_{1}$ 造影が行えなかった。

\section{$2.2 \mathrm{Gd}-\mathrm{YAG}\left(\mathrm{Gd}-\mathrm{YAG}: \mathrm{Yb}^{3+}\right)$ ナノ粒子}

Fig. 1にYAGナノ粒子およびGd-YAGナノ粒子の SEM像を示す。それぞれ粒径は56.0 $10.0 \mathrm{~nm}$ および $55.5 \pm 7.2 \mathrm{~nm}$ であり，両者の粒径の差異は見られない。 両試料のX線回折ピークは単相のガーネット構造に帰 属でき, Gdを後添加したことによる副生成物の生成 は確認されなかった。また，第一強線である（420） ピークは, Gd添加により低角度側にシフトした。こ れはイオン半径の大きな $\mathrm{Gd}^{3+}$ が $\mathrm{Y}^{3+}$ と置換固溶し, 面 間隔が増大したためと考えられる。

Fig. 4にアガロースゲルに分散させたGd-YAGナノ 粒子のMR造影画像を示す。これより Gd-YAGナノ粒
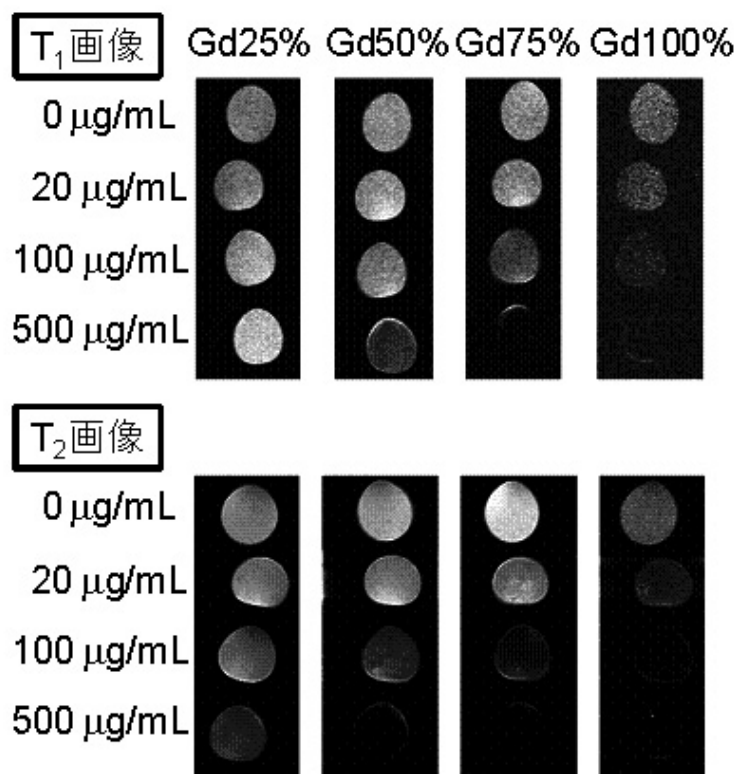

Fig. 3 MR images of (GY) AG.

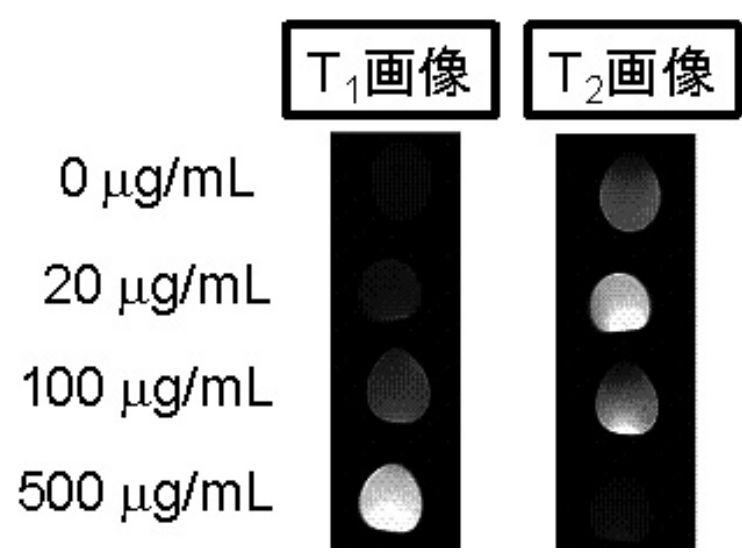

Fig. 4 MR images of Gd-YAG.

子は $\mathrm{T}_{1}$ およ゙゙ $\mathrm{T}_{2}$ 造影剤として機能することが確認さ れ，単位 $\mathrm{Gd}$ 濃度あたりの緩和能 $\mathrm{R}_{1}, \mathrm{R}_{2}$ はそれぞれ $\mathrm{R}_{1}=6.6 \mathrm{mM}^{-1} \mathrm{~s}^{-1}, \mathrm{R}_{2}=56.0 \mathrm{mM}^{-1} \mathrm{~s}^{-1}$ であった。(GdY)AG 固溶体ナノ粒子の場合と異なり, Gd-YAGナノ粒子が $\mathrm{T}_{1}$ 造影剤として機能した理由は次のように考えられ る。Gd-YAG では, GdがYとイオン交換して固溶で きるのは粒子表面近傍だけである。このため, 表面近 傍での $\mathrm{Gd}^{3+}-{ }^{1} \mathrm{H}$ 間の双極子 - 双極子相互作用が十分に 行われ，またGd含有量が少ないため磁化率効果が小 さいので $\mathrm{T}_{2}$ 緩和の影響が抑制され，その結果， $\mathrm{T}_{1}$ 造 影が正常に示されたものと考えられる。また Gd$\mathrm{YAG}: \mathrm{Yb}^{3+}$ ナノ粒子についても同様に $\mathrm{T}_{1}$ および $\mathrm{T}_{2}$ 造 影能が確認され，Fig. 5に示すように，波長940nmの 近赤外レーザーで励起すると, $\mathrm{Yb}^{3+} の^{2} \mathrm{~F}_{5 / 2} \rightarrow^{2} \mathrm{~F}_{7 / 2}$ 遷移 による波長1030 nmをピークとする近赤外蛍光が観測 


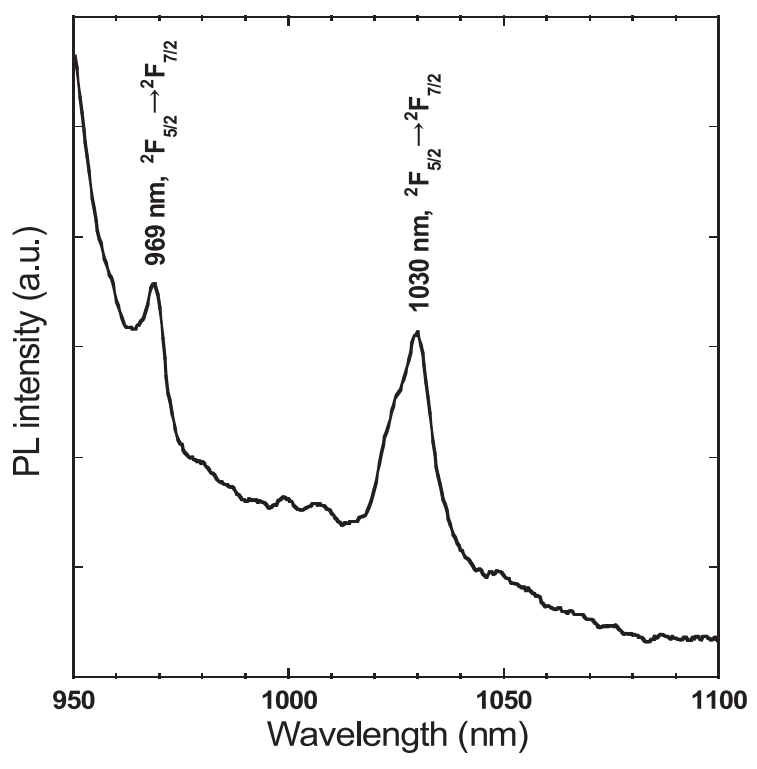

Fig. 5 Near IR photoluminescence spectrum of Gd$\mathrm{YAG}: \mathrm{Yb}^{3+}$ under the excitation by the laser diode $(\lambda=940 \mathrm{~nm})$.

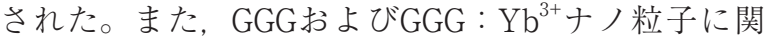
しても，Gd-YAG：Yb $\mathrm{Yb}^{3+}$ ナノ粒子と同様の結果が得ら れた。

\section{3. 結論}

グリコサーマル法により（GY）AG固溶体ナノ粒子 およびGd-YAGナノ粒子を作製した。前者は $\mathrm{T}_{2}$ 造影 鼡，後者は $\mathrm{T}_{1}$ 造影剤として機能した。また， $\mathrm{Gd}-$ $\mathrm{YAG}$ : $\mathrm{Yb}^{3+}$ ナノ粒子は $\mathrm{T}_{1}$ 造影剂として機能すると同 時に, 近赤外励起により $\mathrm{Yb}^{3+} の^{2} \mathrm{~F}_{5 / 2} \rightarrow{ }^{2} \mathrm{~F}_{7 / 2}$ 遷移による 近赤外発光を示し，デュアルモーダルイメージングに 応用できることが示された。

\section{今後の研究の見通し}

Gd-YAG：Yb施林 $G G G ： \mathrm{Yb}^{3+}$ ナノ粒子がマル チモーダルイメージング用プローブとして機能するこ とが確認されたので，今後さらにMRI画像の特性や近 赤外蛍光特性を向上させるための合成方法の改善策を 検討していく。さらに，生体分子イメージングのモデ ル実験を実施することを検討していく。

\section{参考文献}

1) V. Ntziachristos, J. Ripoll, L. V. Wang and R.
Weissleder, Nature Biotech. 23, 313 (2005).

2 ) S. Sivakumar, P. R. Diamente and F. C. J. M. van Veggel, Chem. Eur. J., 12, 5878 (2006).

3 ) W. Jiang, A. Singhal, J. Zheng, C. Wang and W.C.W Chan, Chem. Mater, 18, 4845 (2006).

4 ) G. Yi, H. Lu, S. Zhao, Y. Ge, W. Yang, D. Chen and L.-H. Guo, Nano Lett., 4, 2191 (2004).

5 ) S. Heer, O. Lehmann, M. Haase and H.-U. Gudel, Angew. Chem. Int. Ed., 42, 3179 (2003).

6 ) S.-J. Yu, M.-W. Kang, H.-C. Chang K.-M. Chen, and Y.-C. Yu, J. Am. Chem. Soc., 127, 17604 (2005).

7 ）佐藤慶介, 平栗健二, 舟久保昭夫, 福井康裕, 樋上哲哉, 第54回応用物理学会関係連合講演会講演予稿集 No.3, 28p-ZK-15, p.1524 (2007).

8 ) W. J. Rieter, J. S. Kim, K. M. L. Taylor, H. An, W. Lin, T. Tarrant and W. Lin, Angew. Chem. Int. Ed. 46, 3680 (2007)

9 ) H. Yang, S. Santra, G. A. Walter and P. H. Holloway, Adv. Mater. 18, 2890 (2006).

10) L. Prinzen, R. J. J. H. M. Miserus, A. Dirksen, T.M. Hackeng, N. Deckers, N. J. Bitsch, R. T. A. Megens, K. Douma, J. W. Heemskerk, M. E. Koo, P. M. Frederik, D. W. Slaaf, M. A. M. J. van Zandvoort and C. P. M. Reutelingsperger, Nano Lett. 7, 93 (2007).

11) R. Bakalova, Z. Zhelev, I. Aoki, H. Ohba, Y. Imai and I. Kanno, Anal. Chem., 78, 5925 (2006).

12) W. J. M. Mulder, R. Koole, R. J. Brandwijk, G. Storm, P. T. K. Chin, G. J. Strijkers, C. de Mello Donega, K. Nicolay and A. W. Griffioen, Nano Lett. 6, 1 (2006).

13) W.-B. Tan and Y. Zang, Adv. Mater. 17, 2375 (2005).

14) J. L. Bridot, A. C. Faure, S. Laurent, C. Riviere, C. Billotey, B. Hiba, M. Janier, V. Josserand, J. L. Coll, L. V. Elst, R. Muller, S. Roux, P. Perriat and O. Tillement, J. Am. Chem. Soc. 129, 5076 (2007).

\section{学会発表}

1) Ryo Asakura, Hiroshi Sakane, Kunihiro Noda, Tetsuhiko Isobe, Masahito Morita, Toshiro Inubushi, "Fluorescent and magnetic resonance imaging by rare earth doped nanoparticles with garnet structure”, 2007 MRS fall meeting（2007年11月, Boston)

2 ) 坂根宏志, 朝倉亮, 磯部徹彦, 森田将史, 犬伏俊郎, “近赤外蛍光・MRデュアルイメージング用Gd-YAG: $\mathrm{Yb}^{3+}$ ナノ粒子に関する研究”, 第25回希土類討論会プ ログラム（2008年 5 月，東京） 